\title{
An effective strategy to obtain very rapidly the red palm weevil decline in an area planted with ornamental palms
}

\author{
Michel Ferry ${ }^{1}$, Raphaël Cousin ${ }^{1}$, Daniel Chabernaud ${ }^{2}$ and Frederic Ferrero $^{3}$ \\ (1) Phoenix Research Station, Spain, email: ferry.palm@gmail.com; (2) Propalmes 83, France; (3) CAVEM, France
}

\begin{abstract}
Ferry, M., R. Cousin, D. Chabernaud and F. Ferrero. 2019. An effective strategy to obtain very rapidly the red palm weevil decline in an area planted with ornamental palms. Arab Journal of Plant Protection, 37(2): 188-197.

To control successfully the RPW, it is essential to implement a programme conceived and applied to obtain the pest decline as fast as possible. Such objective is easy to reach when RPW is not yet too widespread and abundant. Unfortunately, in most of the infested countries, it is not at all the case anymore. The challenge now is to propose strategies and technical solutions sociologically, economically and environmentally sustainable. In a territory of five grouped municipalities in the French Riviera, has been applied since 2016 a strategy elaborated by the Phoenix Research Station (PRS) and implemented under the supervision of the inter-municipality authority in charge of this territory (CAVEM). Although the area is heavily infested by the RPW, the objective is to demonstrate that it is possible in few years to stop the palms hecatomb and to obtain a rapid decline of the RPW ("palms" refer generally in this paper to Phoenix canariensis that is by far the main target and main incubator of the RPW). The main challenge, here like everywhere in the infested countries, is to get the palm owners acceptation to the proposed strategy and their collaboration. One essential point that has contributed greatly to face this challenge has been the existence of a very active association of private palms owners (Propalmes 83). To obtain the public and private palms owners collaboration it was fundamental that the proposed strategy be conceived taking into consideration the capacities and economic means of these actors. Therefore, the PRS proposed that CAVEM organize the activities to facilitate as much as possible their grouping to reduce the costs to a minimum. Among the different activities, the PRS proposed that preventive treatment based on an injection technique, because of its much lower cost and its great safety compared with other techniques, be the core of the action plan. This proposal is based on the results of a theoretical analysis presented here on the evolution of the number of new yearly infested palms. This analysis allowed establishing, with a probability of $95 \%$ for the confidence intervals, the number of new yearly infested palms based on the percentage of treated palms. The field results available for the CAVEM territory for 2016 and partially for 2017, confirm the validity of this analysis. These results showed that, if as planned, the objective of $75 \%$ of injected palms on the total number of palms is reached, the number of infested palms will decrease very quickly in 3-4 years, leading to a considerable decline of the native population of RPW and of the number and size of the infested spots, that in addition will be perfectly located. Once this result will be reached, it will become quite feasible to treat all the palms, even with biological agents, in the infested spots and so finally to eradicate the RPW. Of course, the same strategy has to be followed rapidly by the surrounding territories, otherwise such result would be vain as re-infestation will occur.
\end{abstract}

Keywords: Rhynchophorus ferrugineus, Phoenix canariensis, Phoenix dactylifera, IPM, injection treatment, management strategy, participative approach, cost, binomial law, rapid decline, eradication, sanitation of infestation spots.

\section{Introduction}

The red palm weevil (RPW) is a deadly pest of palms species of great economic and environmental importance, especially the date palm and the coconut. It is also a deadly pest of many ornamental palm species, especially the Phoenix canariensis. This specie since the end of the nineteenth century represents the dominant palm specie planted in the cities of the Mediterranean coast, where it is or used to be, at the core of the exceptional and typical landscape of these cities. Unfortunately, it is also by far, the most attractive and less resistant host of the RPW. This pest is capable to attack palms whatever the size (at the difference of the date palm) and, if no action is taken to sanitize the infested palms, it kills them inevitably and rapidly: a large palm can be killed in less than 12 months. The infested Phoenix canariensis constitute also an exceptional incubator for the multiplication of the RPW.

The RPW was introduced in the Mediterranean region in 1993, but it was only at the beginning of the 2000s when it has been dispersed at a large scale and very quickly because of the important legal trade of palms imported from

http://dx.doi.org/10.22268/AJPP-037.2.188197

(C) 2019 Arab Society for Plant Protection الجمعية العربية لوقاية النبات
Egypt and of the legal dispersal of palms from ornamental nurseries infested via the imported palms. Inappropriate phytosanitary regulations are at origin of the general hecatomb of Phoenix canariensis (Ferry and Gomez, 2013). The control of the pest on the Phoenix canariensis in the Mediterranean area, as well as of the date palms worldwide, has been a serious failure (Ferry and Gomez, 2008a; Ferry, in press a), in spite of the fact that the strategy and techniques to control this pest have been established 20 years ago (Abraham et al., 1998; Faleiro, 2006) and they are still nearly the same that are recommended today (Ferry and Al-Dobai, in press). They are also the same that have allowed RPW eradication in some locations (Ferry et al., in press).

The causes of this failure that are quite similar for the ornamental palms and date palms, are now well established (Aldobai and Ferry, in press): absence of strict regulations regarding the movements of palms or insufficient respect of these regulations; flawed governance and monitoring of the RPW control programmes from the local to the national level; serious lack of knowledge of the socio-economic constraints in order to propose suitable organization and means; lack of involvement of the first concerned stakeholders: the palms owners (Abdedaiem et al., in press); 
serious misconception on some aspects of the RPW biology that have led to very costly, unnecessary, counterproductive or inefficient technical recommendations (Ferry and Aldobai, in press; Ferry, in press b).

In numerous cities, especially in the Middle East, where date palms are planted as ornamental trees, the problem of RPW does not present the same degree of seriousness as in the cities of the Mediterranean region, where the main ornamental palm is the Phoenix canariensis. The date palms planted for ornamental purpose are usually be of great dimensions and without offshoots, characteristics that reduce a lot the risk of infestation by the RPW (Ferry and Gomez, 2012; Ferry and Aldobai, in press).

In the cities of the Mediterranean area, as the RPW is now largely widespread and as the control of this pest is inefficient if it is not conceived on a wide area based strategy, the economic constraint is crucial. Furthermore, the exceptional patrimony represented by the Phoenix canariensis palms is threatened to disappear in the short term if efficient programmes to obtain the rapid decline of the RPW are not implemented very quickly.

In addition, in Morocco and in Tunisia, where the RPW is only present presently on Phoenix canariensis in cities in the North of the countries, the risk of an accidental transport of the pest to the oasis increases with time, especially in Tunisia where it is not rare now to find palms at the last stage of infestation (Dr. N. Nasr photo of 13/10/18). In Morocco, a new outbreak was found in Nador in 2016, whose origin is very probably the infested palms of Melilla, where contrary to Ceuta, the RPW has not been eradicated.

In Israel, where the first RPW outbreaks were perfectly eradicated between 1999 and 2002, a new outbreak on Phoenix canariensis in the northernmost city of the country was discovered in 2009. Unfortunately, the management of this new outbreak has followed the same model as the one adopted in Europe. Consequently, the RPW has reached the date palms plantations since 2013 (personal observation) and it is now widespread in large part of the country.

For all these cities that are now very infested, the challenge is to propose strategies and technical solutions sociologically, economically and environmentally sustainable.

In this paper is proposed a strategy that could be implemented at a large scale because it is conceived to minimize the costs and to concentrate the organizational efforts on a short period, at the end of which the RPW will be contained in few and well delimited areas, where the eradication of the remaining RPW becomes perfectly realistic. The first results of implementation of this strategy, obtained in the framework of a project initiated in 2016 by a consortium of five municipalities in South East France, are also presented.

\section{Principles of the Strategy to Obtain a Rapid Decline of the RPW}

The necessity to obtain the rapid decline of the RPW As illustrated in Figure 1 (Ferry et al., in press), it is imperative to design the programs to control the RPW with the objective to obtain its rapid decline. This decline can be easily controlled as it is directly linked to the decline of the number of new infested palms, which is useful to establish at least on a yearly basis.

The scenario $\mathrm{n}^{\mathrm{o}} 1$ (Figure 1 left) corresponds to the situation that resulted from the control programmes in all the European countries and in most of the dates producing countries: exponential growth of the RPW population, exponential hecatomb of the palms and impossibility to contain the pest. Containment of the RPW failed in all the countries where such programmes were applied. It is useless to continue such programmes in the same conditions. If the objective remains to control the pest and to save the palms, programmes based on totally different organization, means or ways to use the available resources must be designed and implemented.

The scenario $\mathrm{n}^{\circ} 2$ (Figure 1 centre) has been implemented for tens of years in some places. It is now clear that the continuation of such programmes is unsustainable. It is, first, very costly to maintain for an indefinite time measures just efficient to avoid the increase of the RPW population, taking also into consideration that they will not prevent a regular hecatomb of palms. Even in countries where considerable financial resources are available, it is now planned to modify such programmes in order to obtain the rapid RPW decline and, consequently, to reduce rapidly their cost. The second reason to modify such programmes is that they are based, among other measures, on the use of chemical pesticides that, in addition of resistance development, have of course on the long term negative health and environment consequences. Thirdly, with time, the risk that the RPW escapes from the zone where these programmes are applied is very high.

The scenario $n^{\circ} 3$ (Figure 1 right) has been successful in all the places where it has been implemented.

In conclusion, to control the RPW means to design and implement programmes whose objective is clearly to obtain the rapid decline of the pest. These programmes must be carefully monitored and quickly modified if the decline of the number of new infested palms does not occur or does not occur enough rapidly.

Regarding the means to dedicate to programmes leading to the scenario $n^{\circ} 3$, a cost/benefit analysis must be conducted. Most of the time, such analysis will demonstrate that the cost to implement such programme is incomparably lower than the cost of losing the palms.

\footnotetext{
Organizational and economic approach to optimize the means and select strategy and treatments

One of the main problems that explains the failure of the RPW control in urban environment has been the great dispersal of the efforts in time and space and the "everyman for himself" behavior. To be efficient, a programme to control the RPW must be conceived and implemented to involve all the stakeholders in an action plan adopted with their participation and supervised by a recognized authority, and associated with the control and strong institutional support of the plant protection organization.
} 


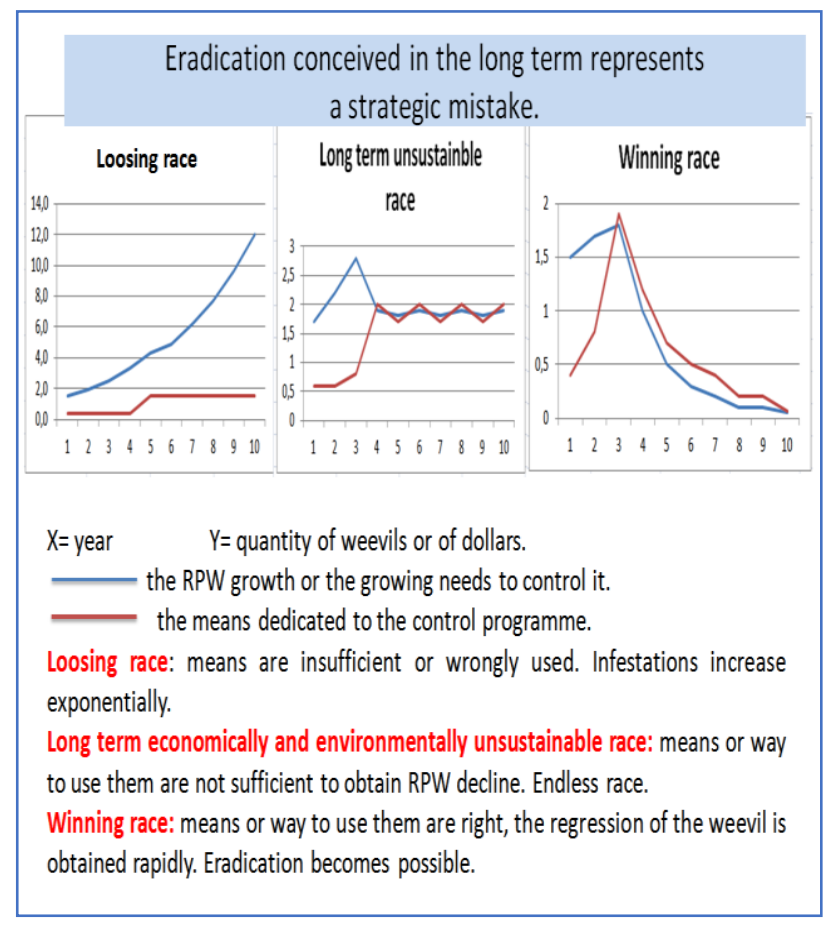

Figure 1. The 3 different scenarios to fail or to succeed the RPW control

In urban environment, the right level of management to implement such action plan is, at the local level, the municipality or, still better, the urban community that groups various municipalities that, furthermore, are very often the owners of an important part of ornamental palms. Municipalities or urban communities dispose, to varying degrees, of different institutional, human and material means that give them the capacity to implement the different tasks of the supervision function: institutional legitimacy; communication, coordination and training capacities and facilities; competence to establish and manage a GIS to manage the program; means to locate the palms owners and the palms (cadastre, orthophotos, etc.); capacity to negotiate collective and to planify the interventions with the objective to reduce as much as possible the cost of the programme for the municipality and the palms owners; capacity under the control of the Plant Protection Authority to establish and to give force to a local regulation and police to control its compliance (Mairie de Vence, 2017).

The strong commitment of the political leaders of the municipalities, with the full institutional support of the Plant Protection authority is of course an absolute prerequisite to give to the municipalities' concerned staff the means to implement the management of the RPW control programme. When this is the case, the efficiency of a municipality to manage a collective plan of action against the RPW is well demonstrated (Paz et al., 2010).

The mobilization of local associations that represent the private palms owners is also essential. Finally, the local action plans must be imperatively coordinated at the regional and national level by the different authority levels in charge of this issue to make sure that it is correctly applied in the whole concerned territory.
The adoption of a collective plan of action will also allow to implement its different components in a much more efficient and less expensive way than if they were implemented in a disperse and individual way. Furthermore, the objective of such plan is to quickly obtain RPW decline. Consequently the organizational efforts as well the cost of the action plan will be as limited as possible in time. This point is very important to facilitate the acceptance of the majority of the stakeholders to contribute to its realization.

Figure 2 represents the different components of the IPM model recommended for more than 20 years to control the RPW. The arrows indicate the strong interaction between the different components (Ferry and Aldobai, in press).

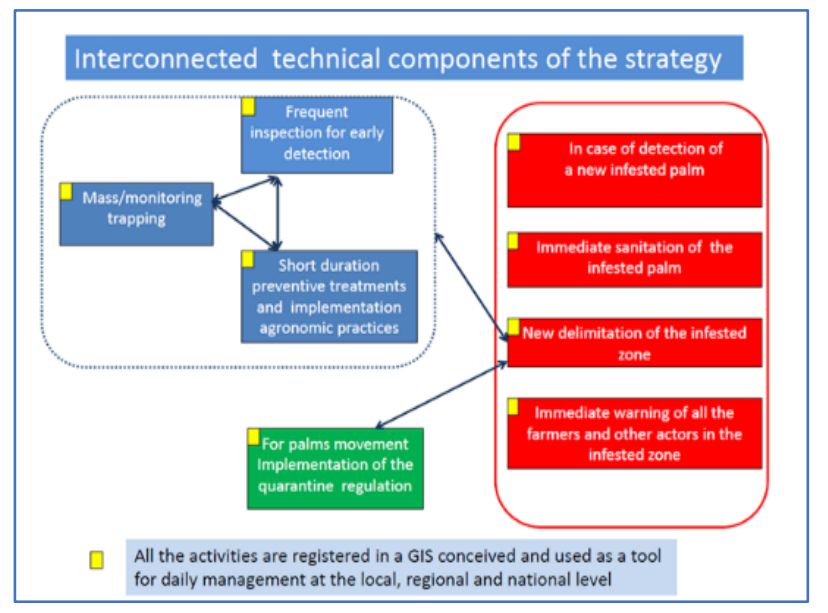

Figure 2. The area-wide integrated strategy to control the RPW.

\section{Frequent Inspection for Early Detection of Infested Palms}

This activity is essential, as the early detection of infested palms allows to eradicate them or preferably to sanitize them, and consequently, to eradicate as soon as possible all the RPW that these infested palms contain. The early detection followed immediately by the sanitation or the eradication of the infested parts of the palms allows to prevent or limit considerably the RPW multiplication as well as the infestation of the neighbouring healthy palms and the RPW spread.

In some places, the inspection task has been entrusted to public or private organizations. This solution is very costly, and when this task has to be paid by the private owners, it is likely not to be implemented at all. Consequently, frequent inspection, even when it was compulsory, has never been applied systematically and at a large scale. As for all the components of the IPM, it has rarely been considered that the main concerned stakeholders, the palms owners or their gardeners, could be efficiently involved in this task if only they were aware and trained and if, in case of detection, the only proposed solution would not have been to eradicate the infested palm (Ferry and Gomez, 2007).

As the visual symptoms of early infestation can perfectly be detected from ground and are now well 
characterized (Ferry and Gomez, 2012), frequent inspection can be implemented by the palms owners or their gardeners with the advantage that they are often present permanently or frequently in the place where are they palms.

The successful implementation of this task by the palms owners is linked to the efforts developed to involve them, as far as possible, in the elaboration and the implementation of the action plan.

\section{Mass Trapping}

For this component, the situation is quite similar to the one described regarding frequent inspection. Entrusting this activity when the objective of the trapping is to contribute to reduce usefully the RPW population (high density of traps) is very expensive. As the instructions for the traps are not complicated, even if they are not of the dry type, the palms owners, their gardeners or any other volunteers can easily manage them (Comune di Marsala, 2009). When possible, the registration of the captures constitutes an essential information to monitor the pest and to control the efficiency of the action plans. Unfortunately, the use in Europe of the traps, excepted for monitoring, is not authorized, as the societies producing the RPW pheromone have not implemented the procedure for its approval.

\section{Sanitation of the Infestation Spots}

In the RPW control programmes, it is very often spoken of curative treatments. This formulation is in fact not appropriate for such programmes as the main objective of these treatments is to eradicate the RPW present in the infested palms. We should speak of sanitation of the infestation spots represented by the infested palms where the RPW multiplies rapidly and from where it spreads if this sanitation is not realized rapidly.

The sanitation of the infestation spots consists of mechanical and/or chemical treatments to kill all the RPW present in the infested palm. If this operation is done in time, the infested palms can be cured, but as already say, it is not the primary objective although it is very important.

Contrary to the previous components, sanitation of the infestation spots (excepted when they are small), presently mainly based on mechanical sanitation, requires experience and equipment that generally prevent the implementation of these operations by the palms owners or their gardeners. The assistance of specialized well equipped professionals is usually necessary. The cost and the complexity of these operations can be seriously reduced once it is understood that infested parts can easily and advantageously be separated from no-infested ones and when the risk presented by the infested parts of the palm and by the wastes is well understood (Ferry and Aldobai, in press). Unfortunately, these operations have been implemented and even enforced erroneously during many years: eradication of palms that could have been sanitized, eradication of the whole infested palms when it is sufficient, easiest, far less costly and quite possible in situ to eradicate only the infested parts. Consequently, this IPM component, although compulsory and fundamental, has been little implemented by the private owners, especially when the infestation was detected late, preventing the rescue of the palms. It has been very often implemented so late that the palms were already killed with the lower crown fronds drying, that means that the palms were no more infestation spots as all the weevils had abandoned them.

By grouping these spot sanitation operations to reduce their cost, by increasing the inspections to detect the infested palms in time to prevent or to stop the RPW spread and to save as much as possible the infested palms, by implementing the other measures of the action plan to reduce considerably the risk of re-infestation, by enacting and enforcing municipality regulation, it would be possible to improve the implementation of this component, thanks especially to a better acceptation by the palms owners.

\section{Preventive Treatments}

In the RPW control programmes, the first objective of the preventive treatments should be conceived as a measure to contribute to RPW rapid decline. The protection of the palms is a consequence, just as the eradication of the infested parts of the palms can cure the infested palms if it is realized in time.

Preventive treatments must be implemented only in the framework of a plan of action conceived with the objective to reach rapidly the RPW decline, otherwise they are not sustainable either for economic reasons and/or for health and environmental reasons.

The palms to be treated are located in the zone (the infested zone) where infested palms have been detected or where weevils have been captured. From these palms will be infested new palms if not action is implemented to avoid it. To establish for sure the limits of the infested zone is impossible. They must be fixed taking into consideration the aggregative dispersal behaviour of the RPW (Faleiro et al., 2002; Massoud et al., 2012). Their limits correspond in fact to a compromise between the operational and financial means that can be dedicated to the measures to implement in these zones and the establishment of the largest possible safety margin.

The preventive treatments are of two types:

(1) Soaking the extreme basis of the fronds that are the target sites of oviposition and adults refuge. Unfortunately to be efficient, the treatments with chemical products or biological agents have to be repeated every 3-4 weeks, and for the tall palms require the use of lift platforms. Consequently, the cost of these treatments is very high and they are rarely applied, even in countries like France, where they are compulsory since 2010 on all the palms located in the infested area (Ministère de l'Agriculture, 2010). In addition, the application of treatments in cities either with chemical products or Beauveria bassiana (but not with nematodes) requires the adoption of complicated regulatory precautions.

(2) Injecting insecticides in the trunk. The problem of these types of treatments is that the plants are not capable to regenerate the wounded tissues and, in addition, the palms are not capable to recover the hole resulting of the injection. Consequently, the injections treatments can't be repeated indefinitely because of the risk of creating necrosis or rotting 
zones in the trunk that could lead to the inacceptable risk of falling palms.

A very simple method of injection of an emamectin benzoate formulation was developed in 2013 (Gomez and Ferry, 2015). With this method and this formulation it was established that it is possible to protect efficiently the palms during one year. Compared with the soaking treatments, the advantages of this method are considerable: one treatment per year, operation from ground level, no need of any special device, very safe treatment (no risk of contact for the operator, no dispersion of the product in the environment), simple and quick operation (2-3 minutes per palm). Consequently, in the countries where similar emamectin benzoate formulations are available, the cost of the treatment per palm and per year is at least 20 times less expensive than the soaking treatments. Unfortunately, in the European countries where this treatment is authorized, the multinational Syngenta that is the owner of the only authorized formulation has imposed a monopoly on the application of the treatment. This monopoly has led to make the treatment much more expensive than if the product had been normally placed on the market. Nevertheless, in France, thanks to CAVEM and Propalmes 83 negotiation efforts, Syngenta has accepted to divide per three the price of the treatment when it is applied inside municipality action plans.

Because of all its considerable advantages compared with the soaking treatments, the adoption of this treatment by an important number of palms owners becomes realistic. It will allow the area-wide implementation of this component of the IPM strategy that, as demonstrated in the second part of this paper, can contribute very efficiently to obtain the rapid decline of the RPW.

\section{Theoretical Approach of the Impact of Injection Treatments to Obtain the Rapid Decline of the RPW}

\section{Equivalence between the decline of the RPW and the number of new infested palms}

It is not possible to evaluate directly the RPW population decline. The decrease of the captures in the traps constitutes a useful indirect parameter, but the best parameter is the decline of the number of new infested palms. It is directly in relation with the decline of the RPW population.

\section{Binomial distribution and confidence interval}

The number of new infested palms depends of the initial number of infested palms, of the percentage of palms protected by injection in infested area and of the yearly reproduction ratio. This last one corresponds to the number of palms that should have been infested if no treatments were applied. When treatments are applied, a part of the palms in the infested area is not infested because not attacked by the RPP; another part is infested because the treatment is not applied on all the palms or is not $100 \%$ efficient; the last part is not infested because they are protected by the treatment.

As the efficiency of the treatment is very high developed by the Phoenix Research Station (Gomez and Ferry, 2015), the number of new infested palms (failed treatments) among the treated ones is very low (around $1 \%$ if we exclude the treatments applied on palms asymptomatic or not detected that were infested before injection. The treatment is not very efficient on such palms if the height of their stipe is of more than 3-4 m).

To simplify the model, we have neglected the number of failed treatments. We have also considered that the infested palms were killed one year after having been infested and so they were no more sources of new infestation after one year. In fact, this simplification has no much effect on the calculation as it does not modify the reproduction ratio.

The number $M_{n+1}$ of new infested palms at the end of the year $n+1$, when the number of infested palms at the end of the year $\mathrm{n}$ was $\mathrm{Mn}=\mathrm{k}$, follows a binomial distribution with parameters ( $\mathrm{r}^{*} \mathrm{Mn}, \%$ of non treated palms). The formula is as follows:

$$
P\left(M_{1}=k\right)=\left(\begin{array}{c}
M_{0} * r \\
k
\end{array}\right) * q^{k} *(1-q)^{\left(M_{0} * r-k\right)}
$$

For $\mathrm{n}>1$, we apply the following Bayes formula:

$$
P\left(M_{n+1}=k\right)=\sum_{j \geq 0} P\left(M_{n+1}=k \mid M_{n}=j\right) * P\left(M_{n}=j\right)
$$

Where $\mathrm{q}=$ proportion of non-injected palms; $\mathrm{r}=$ reproduction ratio; Mo $=$ the initial number of infested palms; $M 1, M n+1=$ the number of new infested palms at the end of respectively the first year and the year $n+1, M n=$ initial number of infested palms the year $n+1 ; j$ and $k$ respectively all the values $\leq \mathrm{Mn}+1$ et $\leq \mathrm{Mn} ; \mathrm{P}(\mathrm{M} 1=\mathrm{k}), \mathrm{P}(\mathrm{Mn})$, $\mathrm{P}(\mathrm{Mn}+1)=$ respectively the probability that $\mathrm{M} 1=\mathrm{k}, \mathrm{Mn}=\mathrm{k}$, $\mathrm{Mn}+1=\mathrm{k}) ; \mathrm{P}(\mathrm{Mn}+1=\mathrm{k} \mid \mathrm{M} 1=\mathrm{j})=$ the probability that $\mathrm{M} 2=\mathrm{k}$ with $\mathrm{M} 1=\mathrm{j}$

The inferior and superior limits of the confidence intervals at $95 \%$ correspond to the values of $\mathrm{k}$ for which the sum of the probabilities for the different values of $\mathrm{k}$ above and below these limits reaches $95 \%$.

\section{The reproduction ratio}

In most of the European countries (excepted especially in the Canaries Islands-Spain), the intervention to control the pest was limited to the eradication of the infested palms, measure that, when it was applied, was applied generally very partially and only during the first 4-6 years after the detection of the first infested palms. Furthermore, it was considered that it was not possible to detect infestation early and impossible to save the infested palms (IVIA 2005; DRAAF 2007). However, the Phoenix Research Station established very soon that these two assertions were erroneous (Ferry and Gomez, 2008b) and that the regulation requiring the systematic eradication of whole infested palms was not at all necessary and would have a very serious counterproductive effect (Ferry and Gomez, 2007; Ferry and Gomez, 2008a). Because of this regulation, the eradication of the infested palms was implemented generally too late, when the palms were nearly killed by the RPW and had released the majority of the adults. Consequently, the propagation of the pest was not much affected by this measure during these first 4-6 years after the first RPW detection. Later, the situation became worse because the fight against the RPW was generally 
totally abandoned and the authorities even stopped to register the number of new infested palms.

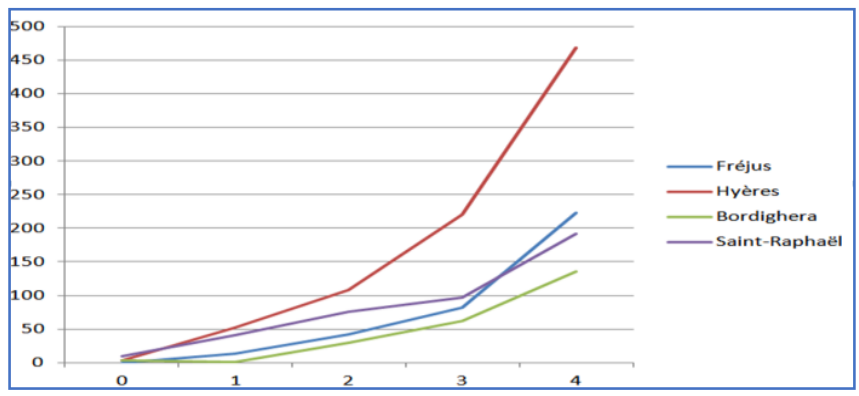

Figure 3. Number of new infested palms/per year in some cities of France and Italy.

The data on the number of new yearly infested palms, when they are available for the first 4-6 years, reflect relatively well the ratio of reproduction of the weevil when no treatment or inefficient treatments are applied. But available precise data on this number are not numerous. Figure 3 represents data available for some cities of France and Italy.

In Hyères and Bordighera, the cities of the palms, the number of new yearly infested palms was fairly well controlled and registered by the local authorities during the first 5-6 years, before, as in most of the European cities, they decide to abandon the control as they realized the ineffectiveness of their strategy. In the other two cities, the number of new yearly infested palms is based on the declaration of the palm owners but it is well established that the corresponding number under-estimated the reality.

Based on these data, it can be estimated that the reproduction ratio in the French Riviera is around 2, i.e. a doubling of the number of new infested palms each year during a first period. Of course, this ratio will decrease rapidly when the number of non-infested palms available in the infested area and around will reach a threshold that will lead the RPW to infest already infested palms in greater number than in the first period.

Evolution of the yearly number of new infested palms according to the percentage of palms protected by the injection treatment

Figure 4 represents the results of the calculation based on the formula mentioned above with a reproduction ratio of 2 and an initial number of infested palms of 500 .

When only $50 \%$ of the palms are treated, the number of new yearly infested palms is constant but with an interval of confidence at $95 \%$ that enlarges quickly. When $75 \%$ of the palms are treated, we observe a very rapid decline: from 500 palms infested initially the number of infested palms decreases, at $95 \%$ of probability, between 19 and 45 after 4 years. The curve is quite similar to the one corresponding to the decrease of the number of new infested palms in the Canary Islands, Spain (Fajardo, 2017) that has led to the eradication of the RPW in this region in 7 years.

Nevertheless, our calculation shows that the number of new infested palms will not reach zero at $75 \%$ treated palms. This result leads to an important conclusion: to reach eradication, only with the preventive treatments, the percentage of treated palms must reach $100 \%$ after the 4 th year. As the number of infested palms has decreased considerably, this option become perfectly feasible, even with more expensive and delicate treatments like soaking the palms with biological agents. Furthermore, complementary measures can be adopted because they have also become practically and economically feasible: intensive mass trapping, intensive inspection for early detection, immediate sanitation of the infested palms. Of course, this eradication success will be totally in vain if around the perimeter where the palms are treated, no similar action is implemented.

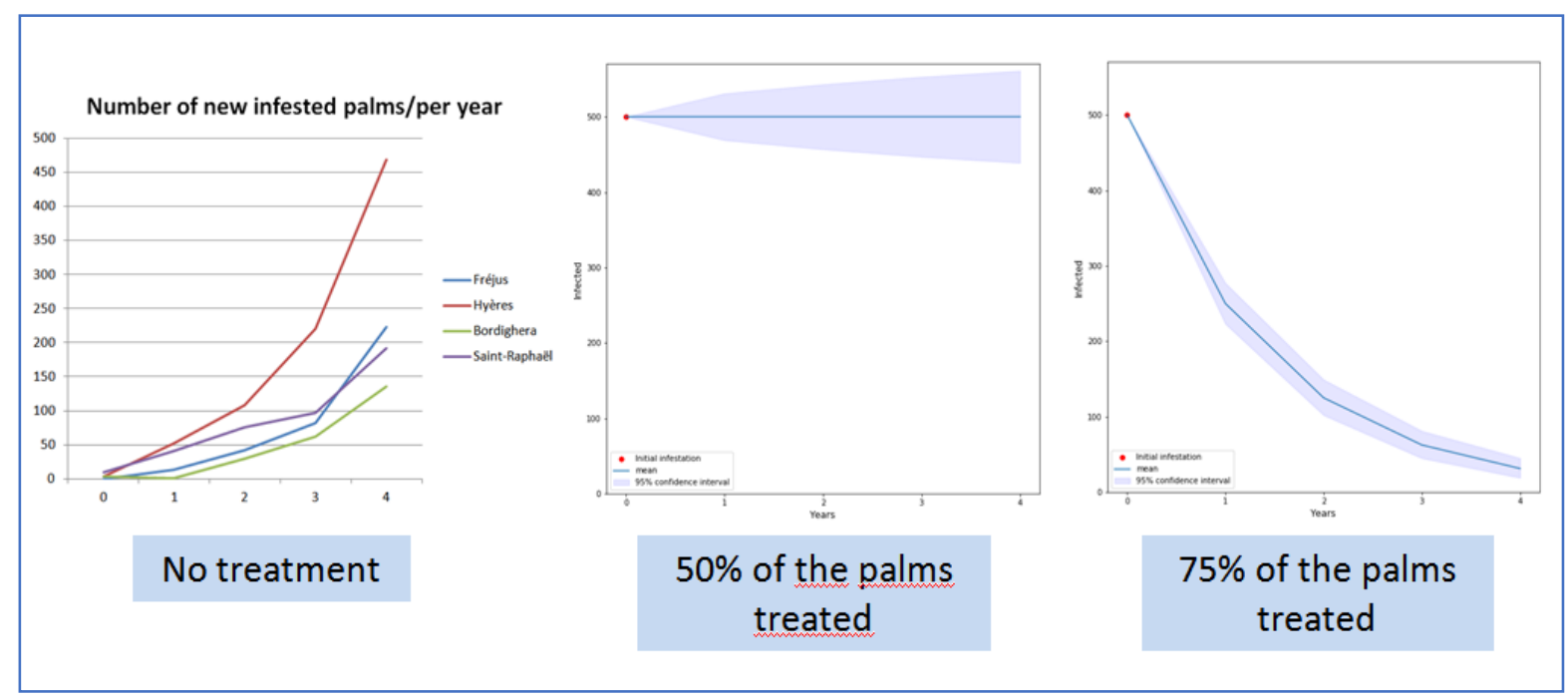

Figure 4. Evolution of the number of new yearly infested palms according to the percentage of injected palms. 
Evolution of the infested areas when $75 \%$ of the palms are injected

Figure 5 simulates the evolution of the number of the new infested palms when $75 \%$ of 10000 palms are protected by injection and with 500 infested palms in year 0 .

Each red circle corresponds to the new infested areas each year taking into consideration the aggregative character of the RPW dispersal. The repartition of the initially infested palms has been done randomly. The repartition of the new yearly infested palms has been done also randomly inside the new infested zone. For each year (Fig. 5-left), are indicated in blue, red, green and black, respectively the number of treated palms, the number of infested ones, the number of non-treated palms, and the number of dead palms.

We remember that to simplify the calculations, we have considered that the palms were killed after one year. We have also considered that no palms were present out of the limit of the perimeter. Consequently, the RPW originated from the infested palms had no other choice but infesting palms in the perimeter and that no RPW could come from outside the perimeter.

Nevertheless, these images simulate well what would occur in a municipality that treats $75 \%$ of its palms, if the municipalities around apply the same strategy. Very quickly the number of new infested zone and of new infested palms will decline, that will facilitate their location as the infested Phoenix canariensis become relatively quickly very visible. Treating all the palms in these remaining infested zone will become perfectly possible leading to the eradication of the RPW.

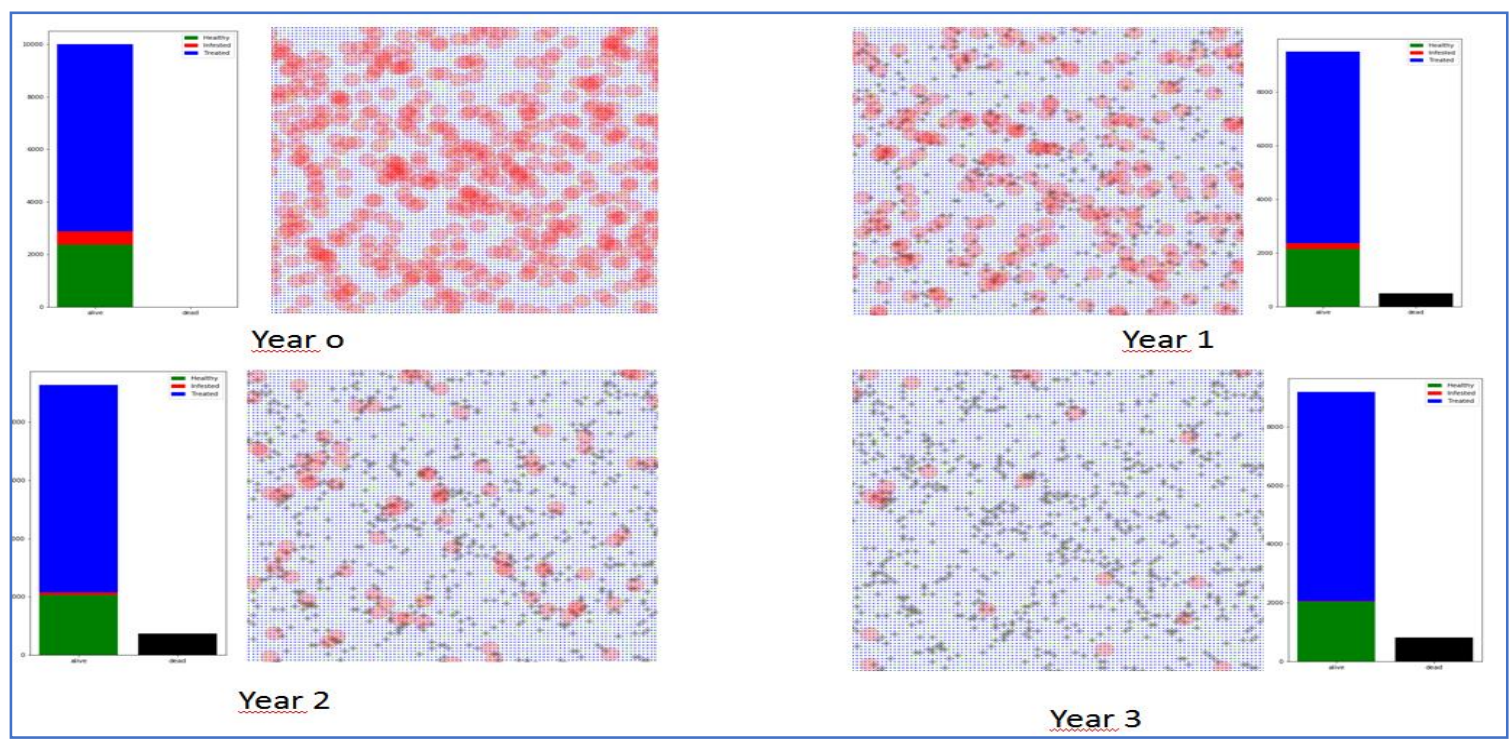

Figure 5. Rapid regression of the number of new infested palms and new infested areas (red circles) when $75 \%$ of the palms are injected.

\section{First Results Obtained in the Framework of the ARECAP Project}

In a territory which includes five grouped municipalities in the French Riviera (Fréjus, Saint-Raphaël, Roquebrunes-surArgens, Puget-sur-Argens, les Adrets de l'Esterel), a strategy elaborated by the Phoenix Research Station has been applied since 2016 and implemented under the supervision of the inter-municipality authority in charge of this territory (CAVEM). Although the area was very infested by the RPW, the objective was to demonstrate that it was possible in few years to stop the palms hecatomb and to obtain a rapid decline of the RPW.

The main challenge, here like everywhere, was to obtain the support of a maximum of palm owners to the proposed strategy and their collaboration. One essential point that contributed greatly to face this challenge was the existence of a very active association of private palms owners (Propalmes 83).

The action plan consisted of:
- Intensive and repeated communication and awareness (mail, media, meeting, hotline) campaigns.

- Website to assist the palms owners for implementing the treatments and to organize, group and register the treatments in coordination with the applicators.

- Management of red of monitoring traps with the assistance of volunteers palms owners.

- GIS to monitor permanently the implementation of the treatments, the results obtained, the evolution of the number of new infested palms in the whole territory, the evolution of captures in the traps, and to locate the priority sectors where efforts must be made to increase the percentage of treated palms and to obtain a quicker intervention on the infested palms

- Negotiation of the price with the company that imposed a monopole on the treatment.

- Geolocation of all the pinnate palms (essentially Phoenix canariensis and Phoenix dactylifera) by visual analysis of Google maps imageries. 
The total number of pinnate palms was estimated at 15000. Taking into consideration that part of these palms were Phoenix dactylifera that are very rarely a RPW host when they are of great size and consequently were not injected, palms too small to be injected, nurseries palms that were treated by soaking treatments, it was estimated that around $50 \%$ of the Phoenix canariensis were treated by injection at the end of the first year.

In the case of CAVEM, as the location of the infested palms at the end of 2015 was unknown, it was not possible to concentrate the treatments in the potentially infested areas. Consequently, all the tall Phoenix canariensis of the territory was considered and the percentage of treated palms was calculated on the basis of total number of these palms. Figure 6 represents the results obtained.

Although the precision of this result is affected by the under-estimation of the number of new yearly infested palms (part of the palms owners do not declare infestation), it showed a clear trend: the number of new yearly infested palms instead of doubling as during the previous years remained similar in 2015 and 2016. The red vertical bar (Fig. 6 ) illustrates this brutal rupture in the evolution of the number of new infested palms. This result was conformed with the result presented in the theoretical approach when $50 \%$ of the palms are treated.

Figure 7 shows the number of palms that would have been infested in 2016 and 2017 if they had not been treated. For 2017, it was considered that the percentage of treated palms was also of $50 \%$. It has been in fact higher. Regarding the conservation of a huge value patrimony, the benefit is evident: 1000 palms have escaped to the hecatomb.

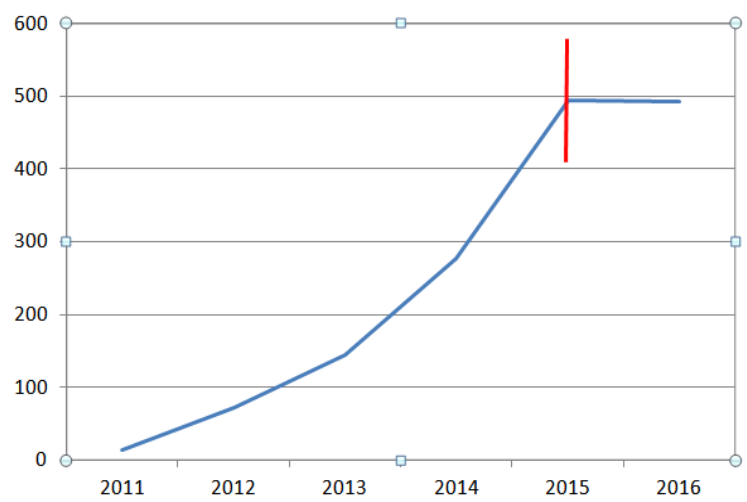

Figure 6. Evolution of the number of new yearly infested palms

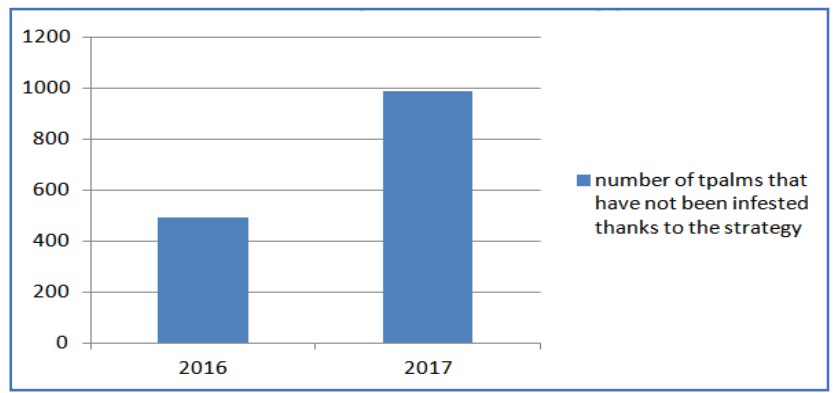

Figure 7. Number of palms that have been attacked but not infested.
Figure 8 shows the direct economic benefit that represented the implementation of these treatments. In this figure, has been represented the cost of eradication of the infested palms that would have been infested without the treatment (in blue) and the benefit (in red) that has resulted from the implementation of the treatments. The benefit has been calculated by substracting the cost of the treatments from the cost of eradication of the palms.

Financially, the benefit is great: it can be considered the municipalities and the private owners globally have saved nearly 500000 euros in 2016 and nearly 700000 euros in 2017.

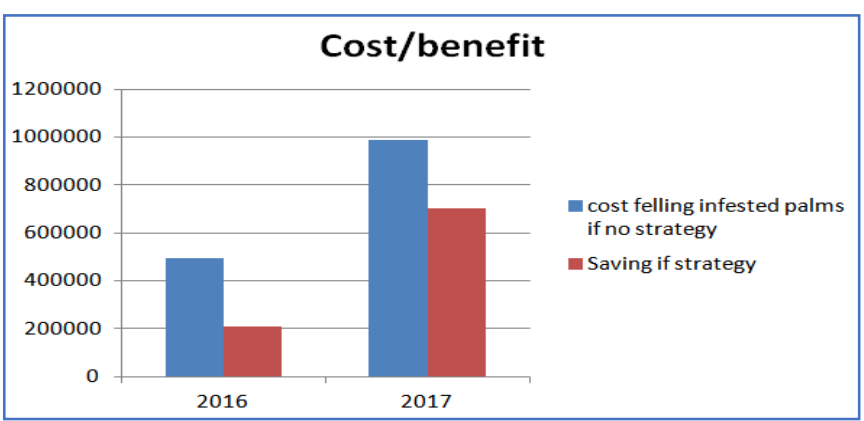

Figure 8. Direct cost/benefice analysis of the adopted strategy in 2016 and 2017.

\section{Conclusions}

The theoretical approach and the first results presented here demonstrate that the strategy proposed to obtain the rapid decline of the pest and to save the palms is feasible and efficient.

We have shown that it was feasible to organize a collective action when the political leaders are convinced and when the directly concerned stakeholders are involved.

Nevertheless, three points have to be highlighted:

- When the three other components of the IPM model (frequent inspection and rapid sanitation of infestation spots; mass trapping) are badly or not implemented, treating only $50 \%$ of the palms leads to an assured failure in the medium term. In case of seriously incomplete implementation of the strategy, the percentage of palms to be treated to obtain rapidly the decline of the RPW is at least of $75 \%$. In CAVEM, the number of treated palms is now closer to this figure. In addition, the municipalities have adopted local regulations that could greatly contribute to the reduction of the number of abandoned infested palms. The number of traps is also now more important and they will also contribute to improve the efficiency of the action plan.

- Our calculation shows that the number of new yearly infested palms will not reach zero at $75 \%$ treated palms. This result leads to an important conclusion: to reach eradication, only with the preventive treatments, the percentage of treated palms must reach $100 \%$ after the $4^{\text {th }}$ year. As the number of infested palms has decreased considerably, this option becomes perfectly feasible, 
even with more expensive treatments like soaking bases of the leaves with biological agents. Furthermore, complementary measures can be adopted because they have also become practically and economically feasible: intensive mass trapping, intensive inspection for early detection, immediate sanitation or the infested palms.

- If such strategy is adopted in an area zone surrounded by other areas where there is no control of RPW, or it is inefficient, this strategy is doomed to fail.

It is then very urgent and important that CAVEM with the institutional support of Plant Protection Authority communicates the results obtained to convince other municipalities and palms owners in France and in Mediterranean region in general that the fight to save the palms is not lost.

In this paper, the palm species concerned was the Phoenix canariensis. But through the adaptation of the strategy and of the preventive treatments to the specificities of other palm species and context, including the date palm in the oasis, the principles of this proposal can be adopted (with a special attention regarding the issue of residue in dates when using injection technique with long insecticide and its possible metabolites persistence. For this reason, for date palm, emamectin benzoate is not appropriate).

On the technical issue, we would like to stress insist on the importance of implementing the preventive treatments only if they are efficient enough to obtain the rapid decline of RPW and are affordable for the majority of the palms owners. The treatment described in this paper is presently the only one that satisfies these two conditions. It obliges to treat with a chemical insecticide but, considering the safety and the short duration of its use (few years), we think that it is quite justified because of the importance of the challenge.

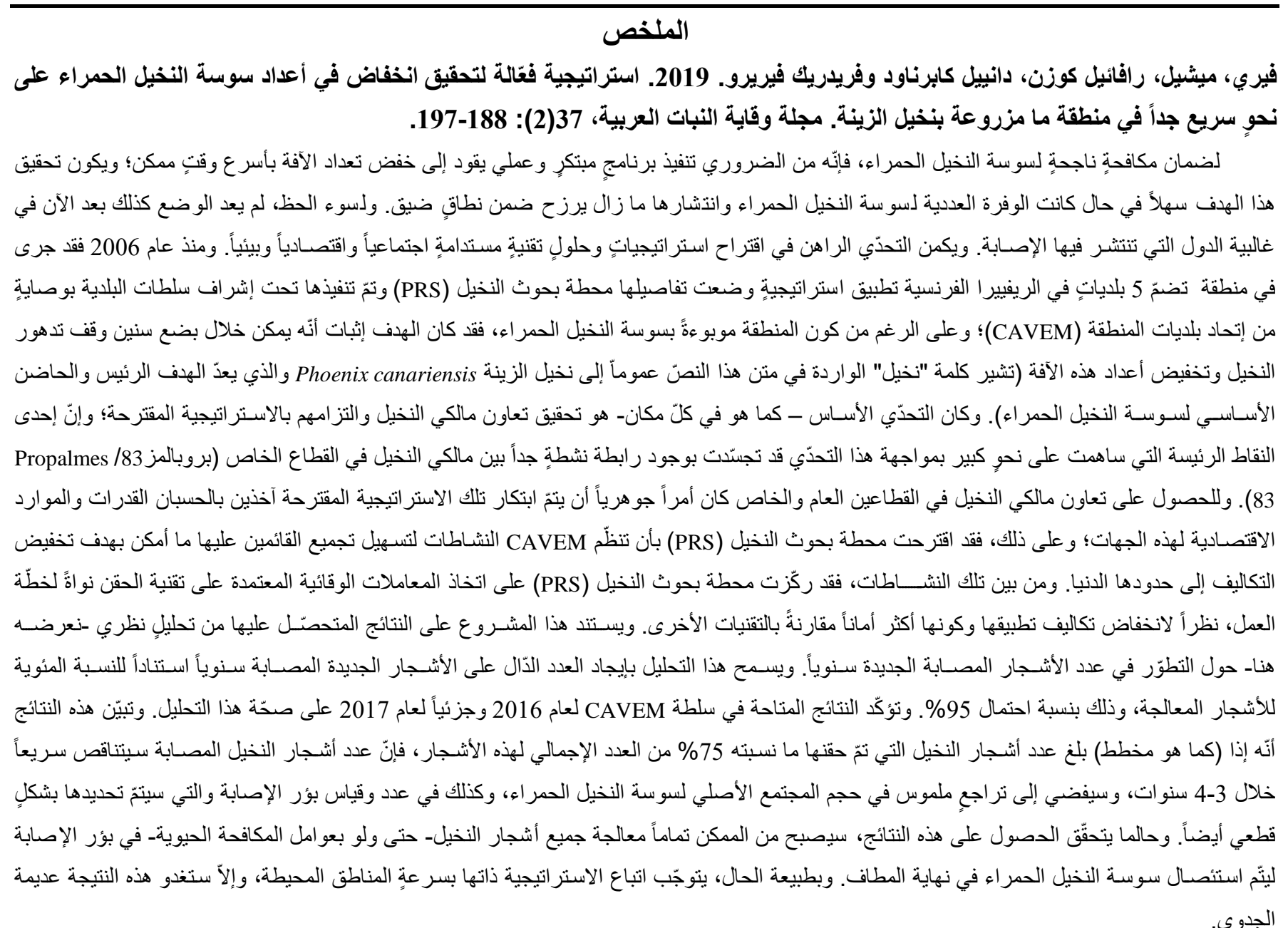

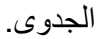

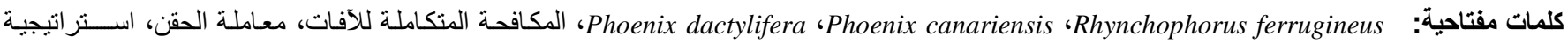
الإدارة، نهج تشاركي، كلفة، قانون ذو حدّين، تناقص سريع، استنئصال، معاملة التطهير.

\section{References}

Abraham V.A., M. Al-Shuaibi, J.R. Faleiro, R.A. Abouzubairah and P.S.P.V. Vidyasagar. 1998. An integrated approach for the management of red palm weevil Rhynchophorus ferrugineus Oliv.- A key pest of date palm in the Middle East. Journal of Agricultural and Marine Sciences, 3:77-83. 
https://doi.org/10.24200/jams.vol3iss1pp77-83

Abdedaiem, S., N. Nasr and M. Ferry (in press). Études et approches socio-économiques pour l'implication des agriculteurs dans le programme de lutte contre le CRP. Proceedings of the "Scientific Consultation and HighLevel Meeting on Red Palm Weevil Management", organized by FAO and CIHEAM, Italy, 29-31 March, 2017, Rome, Italy FAO.

Aldobai, S. and M. Ferry. (In press). Proposed multidisciplinary and multi-regional strategy for the management of RPW. Proceedings of the "Scientific Consultation and High-Level Meeting on Red Palm Weevil Management", organized by FAO and CIHEAM, Italy, 29-31 March, 2017, Rome, Italy FAO

Comune di Marsala - 2 - Lotta Al Punteruolo Rosso: Marsala Aderisce Al Progetto "Adotta Una Trappola" http://www.comune.marsala.tp.it/flex/cm/pages/Serve BLOB.php/L/IT/IDPagina/6454

DRAAF-SRAL. 2007. Compte rendu de la réunion du 8 décembre à HYERES. 8 pp.

Fajardo, M. (in press). The Canary Islands success story in eradicating red palm weevil. Proceedings of the "Scientific Consultation and High-Level Meeting on Red Palm Weevil Management", organized by FAO and CIHEAM, Italy, 29-31 March, 2017, Rome, Italy FAO.

Faleiro, J.R., J. Ashok Kumar and P.A. Rangnekar. 2002. Spatial distribution of red palm weevil Rhynchophorus ferrugineus Oliv. (Coleoptera: Cuculionidae) in coconut plantations. Crop Protection, 21: 171-176. https://doi.org/10.1016/s0261-2194(01)00083-7

Faleiro, J.R. 2006. A review of the issues and management of the red palm weevil Rhynchophorusferrugineus (Coleoptera: Rhynchophoridae) in coconut and date palm during the last one hundred years. International Journal of Tropical Insect Science, 26: 135-154. https://doi.org/10.1079/IJT2006113

Ferry, M. and S. Gómez. 2007. El picudo rojo de la palmera datilera: gravedad de la plaga en España y necesidad de un cambio radical y urgente de estrategia en la lucha. Phytoma, 186: 42-46.

Ferry, M. and S. Gómez. 2008a. L'introduction du charançon rouge des palmiers en Europe: une catastrophe annoncée et largement engagée d'origine purement anthropique. Le palmier, 56: 4-10

Ferry, M. and S. Gómez. 2008b. Une nouvelle stratégie contre le charançon rouge des palmiers. Phytoma, 620: 24-28

Ferry, M. and S. Gómez. 2012. Charançon rouge des palmiers, mises au point sur la lutte. Phytoma, 658:3841.
Ferry M. and S. Gómez. 2013. La lucha contra el picudo rojo: lecciones de un fracaso. La cultura del arbol, 67: 25-37.

Ferry, M. (in press a). Main lessons learnt from 30 years management of the Red Palm Weevil in the world. Presented at the "Scientific Consultation and HighLevel Meeting on Red Palm Weevil Management", organized by FAO and CIHEAM, Italy, 29-31 March, 2017, Rome, Italy.

Ferry, M. (in press b). Recent advances in insecticide treatments against red palm weevil. Proceedings of the "Scientific Consultation and High-Level Meeting on Red Palm Weevil Management", organized by FAO and CIHEAM, Italy, 29-31 March, 2017, Rome, Italy FAO.

Ferry, M. and S. Aldobai. (in press). National components of the strategy for the management of red palm weevil. Proceedings of the "Scientific Consultation and HighLevel Meeting on Red Palm Weevil Management", organized by FAO and CIHEAM, Italy, 29-31 March, 2017, Rome, Italy FAO

Ferry, M., S. Aldobai and H. Elkakhy (in press). The state of art of the control of the red palm weevil. Proceedings of the Sixth International Date Palm Conference, 1921 March 2018, Abu Dhabi. Ministry of Presidential Affairs. UAE.

Gómez, S. and M. Ferry. 2015. Evaluación de la eficacia y persistencia de emamectina benzoato 3,5\% ME, aplicado por inyección en palmeras canarias adultas, en condiciones de campo, en tratamientos preventivos contra Rhynchophorus ferrugineus. SEEA, IX Congreso Nacional de Entomología Aplicada, Valencia, 19-23 de octubre 2015. Libro resúmenes, 91.

IVIA. 2005. Curriculionido ferruginoso o picudo rojo de las palmeras. Site, Informació técnica i económica, 92: 68.

Massoud, M.A., A.A. Sallam, J.R. Faleiro and S. AlAbdan. 2012. Geographic information system-based study to ascertain the spatial and temporal spread of red palm weevil Rhynchophorus ferrugineus (Coleoptera: Curculionidae) in date plantations. International Journal of Tropical Insect Science, 32:108-115. https://doi.org/10.1017/s174275841200015x

Ministère de l'Agriculture. 2010. Arrêté du 21 juillet 2010 relatif à la lutte contre Rhynchophorus ferrugineus. Modifié par arrêté du 9 Août 2018. 13 pp.

Mairie de Vence. 2017 Arrêté du Maire portant obligation de lutte contre le charançon rouge du palmier. Mairie de Vence, 17/08/11. 3 pp.

Paz, S., J. Vidal, M. Ferry and S. Gómez. 2010. Applicacion de la estrategia integrada de erradicacion del picudo rojo en el ambito de un municipio. Phytoma, 221: 49-54. 